\title{
O CLUBE DA RHODIA E OS MORADORES DA VILA HOLÂNDIA - CAMPINAS/SP
}

\author{
Olívia Cristina Ferreira Ribeiro \\ Universidade Estadual de Campinas , Campinas, São Paulo, Brasil
}

\begin{abstract}
Resumo
Este trabalho é parte de uma pesquisa mais ampla, denominada 'Usos do tempo livre na Vila Holândia', na qual investigamos quais as práticas, os espaços e os lugares de referência para a fruição do tempo livre. O Clube da Rhodia foi um dos espaços para o tempo livre e fruição do lazer apontado como importante pelos moradores dessa Vila, situada no distrito de Barão Geraldo, Campinas, São Paulo. Assim, o objetivo deste estudo foi compreender a relação do Clube com os moradores da Vila Holândia e dos mesmos com o Clube, no tempo denominado livre e nas práticas corporais promovidas pela Instituição. Teve como propósito diagnosticar quais práticas corporais vivenciadas no Clube da Rhodia são relevantes para os moradores da Vila Holândia, assim como identificar qual a relação/impacto que elas produzem no tempo livre fora do Clube. Foram realizadas pesquisa bibliográfica, observação e entrevistas semiestruturadas. As análises mostraram que a ginástica, a musculação e o futebol são as práticas corporais mais significativas para os moradores. O futebol é a prática corporal mais vivenciada pelos homens, tanto no Clube, como na comunidade e em outros espaços da cidade. Ele proporciona outros tipos de interação além da sociabilidade em si.
\end{abstract}

Palavras chave: Clube da Rhodia. Tempo Livre. Lazer. Práticas Corporais. Sociabilidade.

\section{Introdução}

Este estudo é parte de uma pesquisa mais ampla, denominada 'Usos do tempo livre na Vila Holândia' (AMARAL et al., 2009), na qual investigamos quais as práticas, os espaços e os lugares de referência para a fruição do tempo livre dos moradores da Vila Holândia. O clube da Rhodia foi um dos espaços para o tempo livre e para a fruição do lazer apontado como importante pelos moradores da Vila, que se localiza no distrito de Barão Geraldo, município de Campinas, SP, tanto da óptica da frequência, como também foi apontado como local desejado pelos moradores daquele lugar.

Diante destes dados iniciais, pareceu-nos interessante pesquisar sobre as relações dos moradores com as práticas corporais existentes no Clube da 
Rhodia, procurando entender como tais atividades poderiam ou não influenciar na fruição do tempo livre no cotidiano de suas vidas. Também nos interessou estudar como os moradores se apropriam deste espaço de lazer e como interagem nele. As questões que nortearam este estudo foram: quais são as práticas corporais mais vivenciadas no clube pelos seus frequentadores, em especial por aqueles oriundos da Vila Holândia? Há algum tipo de interação entre os moradores durante essas práticas? Qual a relação dessa Instituição com o tempo livre e as práticas corporais dos moradores da Vila Holândia?

Assim, os objetivos foram: compreender a relação do Clube com os moradores da Vila Holândia e dos mesmos com o Clube, especialmente naquele tempo denominado livre e nas práticas corporais promovidas pela Instituição; diagnosticar quais práticas corporais vivenciadas no Clube da Rhodia são relevantes para os moradores da Vila Holândia e, ainda, como eles se interagem nessas; identificar qual a relação/impacto que estas produzem no tempo livre fora do clube.

Quanto aos procedimentos metodológicos, foram realizadas observações e entrevistas com os sujeitos que se mostraram mais relevantes para o propósito do estudo.

O Diretor de Esportes do Clube recebeu o projeto e, após análise, autorizou a realização da pesquisa, que foi submetida ao Comitê de Ética em Pesquisa da Unicamp, recebendo autorização.

Assim, observamos o cotidiano tanto dos moradores da Vila que utilizam o Clube, quanto de outras pessoas que frequentam essa Instituição em seus respectivos tempos livres, as práticas corporais promovidas pelo Clube e as mais vivenciadas pelos usuários. O Clube da Rhodia no seu cotidiano, sobretudo no período identificado como tempo livre, enquanto são vivenciadas as práticas corporais promovidas pela Instituição ou mesmo organizadas espontaneamente pelos próprios usuários, foi o locus principal.

Esta aproximação inicial com os usuários do Clube nos auxiliou a identificar elementos relevantes para uma compreensão da realidade estudada, de acordo com o tema. A partir disso, estabelecidos os focos de aprofundamento, incluindo sujeitos e formas de apropriação, foram abordados por meio das entrevistas semiestruturadas usuários significativos do Clube: todos adultos, funcionários da empresa Rhodia, alguns de seus familiares e moradores da Vila Holândia.

De forma mais detalhada, a pesquisa se desdobrou da seguinte forma: durante um ano e três meses, realizamos visitas no Clube da Rhodia. Iniciamos a pesquisa de campo com as observações. Após dez visitas, iniciamos o contato com os moradores associados para a realização das entrevistas. O Diretor de Esportes e professor de musculação nos auxiliou com in- 
formações relevantes, como, por exemplo, a identificação, entre seus alunos, daqueles que eram moradores da Vila Holândia e como ocorria a frequência destes. Também fizemos contato com outros professores das diversas práticas corporais oferecidas no Clube, bem como observamos algumas aulas dos adultos, foco deste estudo.

As observações foram iniciadas em Julho de 2009, período de férias escolares, e terminaram com as entrevistas em Outubro de 2010. Desde o início das observações, procuramos promover uma relação de simpatia com os funcionários, principalmente com as secretárias, os porteiros e o dono da cantina. Todos nos auxiliaram com dados relevantes.

As observações e o contato com funcionários e professores do Clube revelaram que a musculação, a ginástica e o futebol são as práticas corporais com a maior frequência dos moradores da Vila Holândia. Estes dados se confirmaram, também, nas entrevistas semiestruturadas realizadas com dez associados, funcionários da empresa Rhodia e frequentadores: seis praticavam futebol, dois praticavam ginástica e dois praticavam musculação, todos moradores da Vila Holândia. Também foram entrevistados outros oito exassociados que, em pesquisa citada (AMARAL et al., 2009) afirmaram já ter frequentado o Clube e atualmente não o fazem mais.

\section{A Vila Holândia, tempo livre e lazer}

A Vila Holândia se localiza a seis quilômetros do centro do distrito de Barão Geraldo, às margens da estrada da Rhodia. É composta por três pequenas ruas, Caieiras, Cerquilho e Servidão, que são interligadas em formato de "U" e é onde se encontram as residências dos moradores. A Rua Servidão tem um prolongamento, onde se encontram pequenos sítios. Moram na vila cerca de 400 pessoas. ${ }^{1}$

A Vila é cercada por condomínios fechados e, atrás, há a Mata do Quilombo. Esta é um espaço de lazer significativo para os moradores da Vila, citada nos questionários aplicados pela pesquisa mais ampla. A caminhada foi considerada como a principal atividade de lazer praticada naquele local.

As ruas constituem-se em espaços também importantes para os moradores da Vila. Observamos que elas são locais de encontro, bem movimentadas aos finais de semana, onde crianças e adultos conversam, brincam e circulam, o que revela a existência de uma vida comunitária ainda significativa.

1 Não conseguimos dados oficiais do número de habitantes, mas a pesquisa de Amaral et al. (2009) mostrou o número aproximado destes.

Pensar a Prática, Goiânia, v. 17, n. 3, p. 651-666, jul./set. 2014 
Além das ruas, outros espaços parecem constituir pontos importantes para essa dinâmica social local, tais como o Centro Cultural Casarão do Barão, a Fazenda Quilombo, diversos bares, duas igrejas - uma católica e outra evangélica - campos de futebol, a Escola Estadual Francisco Álvares e o Clube da Rhodia, tema deste estudo.

A Vila Holândia é considerada, ainda, um bairro rural, mas o caminho do centro de Barão Geraldo até lá demonstra o quanto as transformações sofridas nos últimos anos têm constituído um cenário de aparente expropriação dos espaços de convívio comunitários. Na Estrada da Rhodia, utilizada pra chegar até a Vila Holândia, vários outdoors são encontrados e anunciam a exploração imobiliária local, por meio de promessas de divertimento, lazer, segurança, contato com o verde e muito mais, que, provavelmente, não são direcionados aos moradores da Vila.

O entorno da Vila Holândia é um dos locais onde há grande venda de imóveis e também há, na internet, dados de vários projetos de educação ambiental, o que denota uma preocupação pela preservação ambiental da região e uma tensão, nas últimas décadas, de duas cidades metafóricas: a cidade imobiliária e a cidade ambiental (CALDEYRO, 2005). A primeira é constituída por setores da sociedade civil interessados no ganho especulativo com a venda de terra, cujo avanço, em grande medida, tem obtido sucesso, graças à política da cidade. A segunda consiste numa resistência e contraponto à primeira e condiz com a preocupação e com a ação de outros atores a fim de preservar as áreas verdes, com mata nativa, nascentes e mananciais que ainda existem na região.

Tais temas constituem polos opostos, uma vez que a degradação ambiental, vinculada ao lixo e à sujeira que o Ribeirão Anhumas traz após atravessar toda a cidade, tem relação, também, com a devastação causada pela expansão urbana.

Essa tensão por novos empreendimentos imobiliários e os jogos políticos cederam lugar a um novo modelo urbanístico, importado dos norteamericanos: condomínios que prometem amplo contato com a natureza vasta ao redor, além de segurança e lazer.

Esse tipo de iniciativa foi a resposta das classes sociais de poder aquisitivo mais elevado à crescente violência urbana. Contudo, a exclusão do outro também parece excluir a diversidade do convívio com a diferença. As classes sociais de menor poder aquisitivo, dessa forma, ficaram à mercê da própria sorte. Isso é percebido pelos moradores da Vila Holândia, que afirmam que se o "progresso chegou", por outro lado, ele "tirou o sossego". Hoje, há mais preocupação por causa das casas. "Dois lados da moeda: desenvolvimento econômico da região e aumento da marginalidade" (AMARAL et al, 2009, p.6). Caldeyro ainda afirma que o que define os espaços 
urbanos hoje é o consumo, "é a busca pela melhor acessibilidade, e está relacionada com o menor tempo de deslocamento e equipamentos de comércio e serviços" (2005, p. 80).

Barão Geraldo e a área da Vila Holândia são dotados de externalidades positivas, ou seja, há várias empresas de grande porte próximas ao local, um sistema viário que dá acesso a diversas cidades da Região Metropolitana de Campinas e a bairros da própria cidade. Há, também, um exponencial aumento de estabelecimentos comerciais de diversos setores e uma necessidade crescente pelo serviço doméstico e da construção civil.

Tal fato é percebido pelos moradores da Vila Holândia como positivo. Quando perguntados sobre o progresso, alguns responderam "achamos bom ter os condomínios, pois isso trouxe progresso à região, empregos, padaria". Entretanto, outros percebem que esse progresso trouxe também exploração e afirmaram, quando perguntados sobre isto: "as mesmas coisas só cresceram, o bairro da frente (condomínios) trouxe ônibus que passam pela Vila, trazendo insegurança para as crianças e assaltos, nada de novo para nós" (AMARAL et al, 2009).

Dessa forma, os espaços para a fruição do tempo livre e do lazer foram modificados e, hoje, restam poucas opções, algumas delas não acessíveis a todos os moradores. Dentre essas opções está o Clube da Rhodia, como comentado.

\section{Os clubes como espaços de lazer}

Os clubes podem ser conceituados como associações voluntárias e democráticas, apesar de, historicamente, também apresentarem um aspecto aristocrático, aponta Burke (2002). São associações em que pessoas com interesses comuns se reúnem com diversificados objetivos, como contato social, troca de informações, participação em atividades de lazer, etc.

A palavra clube, para muitas pessoas, está relacionada exclusivamente às elites, principalmente na Inglaterra. Tais associações voluntárias foram importantes no Ocidente, principalmente nos séculos XVIII e XIX, porém suas raízes são muito mais antigas e estão associadas ao final da Idade Média, como comenta o autor.

Em Londres, a ascensão dos clubes foi incentivada pela urbanização. A cidade cresceu devido à imigração e os clubes eram uma forma de integrar os recém-chegados, fazendo-os sentirem-se em casa.

No século XVIII, tanto em Londres como em outras cidades, houve o surgimento de uma grande variedade de clubes com interesses especiais: clubes de tocadores de sinos, de debates, e muitos outros. O lazer não ficou de fora, como o clube de música e de esporte. O English Jockey Club tem 
suas origens no século citado e o mesmo aconteceu com os clubes de críquete ingleses e os de golfe escoceses. Houve um desenvolvimento dos clubes em vários países da Europa e América Latina (BURKE, 2002).

De acordo com Camargo (1998), no Brasil, os clubes são instituições com caráter lúdico e tiveram uma grande expansão, desde o início do século XX e se apresentam sob diversos tipos.

Ribeiro (2004, p. 95) classifica os clubes em: "sem e com finalidades lucrativas". Os clubes sem finalidades lucrativas são aqueles mantidos pelos associados, por meio das anuidades, das contribuições e da receita de atividades dos próprios sócios. Esse tipo de clube pode ser caracterizado como urbano e de campo. Ambos os tipos oferecem espaços/equipamentos de lazer e de recreação variados. A diferença é que os clubes de campo localizam-se, normalmente, fora da cidade e possuem amplas áreas verdes e, ainda, quadras e ginásios poliesportivos, campos de futebol, piscinas, salas de ginástica, salões de festa, playgrounds, saunas, entre outros. As dimensões desses clubes e o que eles disponibilizam de espaços e equipamentos de lazer para os associados são variados. Podem oferecer, ainda, lagos e lagoas e são denominados de clubes social-recreativos (RIBEIRO, 2004)

$\mathrm{Na}$ categoria de clubes sem finalidades lucrativas, ainda existem aqueles "mantidos por instituições de classes profissionais, também denominados de grêmios e Associações Desportistas Classistas - ADCs" (RIBEIRO, 2004, p. 95). Tais tipos também podem, ainda, ser urbanos e de campo com dimensões e espaços de lazer bastante diversificados. São mantidos por "verbas das empresas e dos funcionários que contribuem com uma mensalidade simbólica". (RIBEIRO, 2004, p. 95)

Os clubes privados com finalidades lucrativas "são aqueles que possuem uma administração voltada para o lucro. Podem ser mantidos também por meio de mensalidades, ou pela cobrança de ingressos na entrada". (RIBEIRO, 2004, p. 95)

Segundo Camargo (1998), os exemplos são muitos: clubes recreativos urbanos, clubes de campo, clubes aquáticos, clubes de vela, iates-clube etc.

\section{O Clube da Rhodia}

A Associação Desportiva Classista Rhodia Paulínia, clube que os moradores da Vila Holândia frequentam, foi fundada em 19 de Maio de $1946^{2}$, com o nome de Rhodia Clube Campinas. Nessa época, tinha como

\footnotetext{
Paulínia, SP.

A empresa de produtos químicos Rhodia Brasil Ltda foi instalada em 1942, em
} 
sede a fazenda São Francisco, da Rhodia. Nessa sede, também havia as colônias em que habitavam todos os seus funcionários, bem como todos os serviços oferecidos a eles, como, por exemplo, cooperativa de alimentos, farmácia, creche e atendimento médico e odontológico. Ainda existia uma capela, em que funcionários frequentavam missas, realizavam batizados e outras atividades religiosas.

Nessa fazenda, havia espaços espalhados nos quais aconteciam as atividades de lazer do clube: atividades esportivas nas quadras e campos e bailes no casarão, na sede da fazenda. Também havia um parque onde as professoras acompanhavam as crianças em suas atividades (CONJUNTO PAULÍNIA 50 ANOS, 1992).

A distância das cidades e o difícil acesso a elas, por causa das condições das estradas de terra, acabavam por isolar os funcionários. Tais dificuldades motivaram a fundação do clube. Assim, em 1952, a empresa inaugurou uma sede do Clube Rhodia, com vários espaços específicos para a vivência das atividades de lazer. Nessa sede havia quadras poliesportivas, campos de futebol, canchas de bocha, salão com palco e uma piscina.

A programação de lazer era organizada pelos próprios funcionários. Alguns homens participavam da gestão do Clube Rhodia, e algumas senhoras também auxiliavam na organização dos eventos.

As práticas corporais oferecidas consistiam em aulas e treinos de futebol de campo e de salão, basquete, tênis, vôlei, malha e bocha para os homens. As mulheres treinavam somente basquete. Também jogos de mesa eram oferecidos. Havia, ainda, campeonatos de todas essas modalidades.

O clube, o que tinha, era um grêmio, era aqui dentro mesmo, tinha um salão que as pessoas iam jogar pebolim, sinuca. O que era muito forte era o futebol. Tinha o time amador da Rhodia, o pessoal vinha, tinha o campo de futebol, futebol de salão e o salão do clube (Sic) (CONJUNTO PAULINIA, 1992, p. 10).

Semanalmente, aos sábados, havia no Clube exibição de filmes e, aos domingos, programas de calouros com premiação aos ganhadores. Ocasionalmente, eram oferecidos, também, shows de cantores famosos e, ainda, apresentação de circo.

Um calendário de festas diversas também estava à disposição de todos os associados: festa do chope, do primeiro de maio, do dia das mães, junina e coroação da rainha do clube eram as mais importantes e aguardadas pelos associados. Nessas festas realizavam-se atividades recreativas. Na festa junina, por exemplo, havia apresentação de uma quadrilha dos funcionári- 
os, cujos ensaios começavam no mês de Maio. O carnaval era comemorado por meio de bailes noturnos para adultos e matinês para as crianças. Havia concursos de fantasias para os adultos, com premiação.

Por questões de segurança a empresa retirou, aos poucos, todos os moradores da propriedade, o Clube também foi desativado e foi instalado próximo dessa antiga sede. Então, desde Fevereiro de 1993, o Clube se encontra no Jardim do Sol, distrito de Barão Geraldo, Campinas, SP, a dois quilômetros da Vila Holândia. Possui uma área de 52 mil metros quadrados e conta com seis mil associados em seu quadro social.

O clube atende principalmente aos funcionários, aposentados e familiares da empresa Rhodia Brasil Ltda, unidades de Campinas e Paulínia. Ainda podem se associar os funcionários e empresas associadas no conjunto Rhodia Paulínia, os atletas representantes da empresa Rhodia, os honorários e beneméritos e, também, os moradores de bairros vizinhos (ESTATUTO ADCRP, 2009). Os bairros que estão incluídos são o Jardim do Sol e a Cidade Universitária, porém não consta a Vila Holândia, embora os moradores do bairro estudado o reconheçam como espaço de lazer. De acordo com dados da secretaria do clube havia cerca de 33 titulares $^{3}$ associados que eram moradores da Vila Holândia.

Os associados dispõem das seguintes instalações: piscinas, quadras de tênis e outras poliesportivas, cancha de bocha, campos de futebol e vôlei de areia. Contam, ainda, com um salão social e lanchonetes. Há, também, american bar, quiosques com churrasqueiras, bosque e jardins.

A programação de lazer oferecida é diversificada: eventos sociais (bailes, festas, jantares), aulas de dança de salão, de natação, de hidroginástica, de ginástica localizada, de karatê, de judô, de tênis de campo, musculação e escolinha de futebol.

O Clube organiza também, desde seu início, campeonatos internos de várias modalidades: truco, sinuca, futebol de campo, futebol de salão, tênis de campo, bocha, vôlei de areia e de quadra e basquete.

\section{Práticas corporais no Clube da Rhodia: sociabilidade e apropria- ção pelos moradores da Vila Holândia}

Ao analisarmos o Clube da Rhodia, ativemo-nos, como já explicitado, à importância desse espaço para os moradores da Vila Holândia, às práticas corporais por eles vivenciadas e ao impacto destas em suas vidas

\footnotetext{
3 Não nos foi informado o número de dependentes destes sócios titulares. Alguns moradores da Vila Holândia frequentam o clube por meio do pagamento de uma diária ou um de mês "corrido", desde que apresentados por um sócio titular.
}

Pensar a Prática, Goiânia, v. 17, n. 3, p. 651-666, jul./set. 2014 
cotidianas. Acreditamos que o Clube é um espaço de sociabilidade, pois, como afirma Simmel (1983 apud GONZALEZ, 2007), a sociedade se caracteriza pela interação entre indivíduos. Para o autor, essa interação se distingue "pela forma - a maneira como as associações acontecem - e do conteúdo - o porquê de elas acontecerem" (SIMMEL, 1983 apud GONZALEZ, 2007, p. 19).

A interação acontece por meio de certos impulsos, ou objetivos, que formam as bases das sociedades humanas. Por outro lado, a forma seria a associação, pela qual os indivíduos se agrupam em unidades que satisfazem seus interesses, sendo esta de inúmeras maneiras, enfatiza Simmel (1983 apud GONZALEZ, 2007).

Ao interpretar e compreender Simmel, Gonzalez (2007) afirma que há associação na qual, "pelo menos na aparência, se liberam do propósito de alcançar metas e fins da/na realidade" (GONZALEZ, 2007, p.19). São associações em si mesmas, ou seja, que acontecem destituídas de outro interesse que não o de estar com o outro. Gonzalez (2007, p.20) esclarece que, para "alcançar a condição lúdica de associação, os participantes não podem ter pretensões objetivas para além do exercício da interação isso é denominado de sociabilidade".

Simmel (1983 apud GONZALEZ, 2007) exemplifica tal associação, enfatizando que ela pode ser encontrada no jogo e na arte, e isso também é denominado de sociabilidade. Gonzalez (2007, p.20) entende que "a sociabilidade exclui outro tipo de associação ou vice-versa", contudo nossa experiência no campo desta pesquisa tem demonstrado que a associação e a sociabilidade podem estar no agir humano, num continuит.

A musculação e a ginástica no Clube eram procuradas por aqueles que estavam mais afetos à estética, mas a preocupação com a saúde e a qualidade de vida também foram citadas pelos entrevistados: "faço musculação porque quero manter o peso e me sentir bem" (Entrevistada 3); "pratico a ginástica, pois sei que faz bem para a saúde, melhora minhas dores nas costas e porque durmo melhor também. Fazer ginástica para mim é ter qualidade de vida" (Entrevistada 6). Entretanto, ao observarmos este espaço e outros, foi possível notar que os moradores usufruem dos mesmos na perspectiva da sociabilidade.

Em ambas as práticas corporais - musculação e ginástica -, há períodos de menor frequência, no inverno e nos dias chuvosos, o que não acontece com o futebol. Este, mesmo com chuva, é praticado pelos associados, inclusive por aqueles moradores de outros bairros mais distantes do Clube. $\mathrm{O}$ futebol se mostrou como uma das práticas mais relevantes, com uma frequência significativa dos associados do sexo masculino. Dizem alguns: "Ah, o futebol? Mesmo com chuva a gente aparece... é muito bom, né? (Entrevis- 
tado 2)". Outra entrevistada nos fala o mesmo: "eu faço ginástica, mas meu marido joga futebol lá e vai mesmo com o tempo ruim" (Entrevistada 1). O professor de musculação também confirmou esse dado, comentando que, às vezes, com chuva, a sala em que ele atua está vazia, o que não acontece com o campo de futebol.

Outros associados salientaram assim o futebol: "Para mim, o futebol é a possibilidade de relaxar, de divertir, de ter qualidade de vida. Nele, também encontro com os amigos. Não consigo ficar sem jogar" (Entrevistado 8); "no futebol, vejo os amigos, distraio e ponho para fora toda a tensão do trabalho, não fico sem jogar" (Entrevistado 10); "Para mim, o clube é um local para rever os amigos, jogar futebol e relaxar" (Entrevistado 7).

Outro dado importante referente ao futebol é que, mesmo quando os campos estavam em manutenção (Dezembro a Fevereiro), os associados não deixaram de praticá-lo. Organizaram-se na própria Vila Holândia e em bairros próximos para praticar este esporte, conforme a fala de um dos moradores: "Quando o campo do Clube está fechado, nós jogamos no Euroamérica, em Barão Geraldo, ou mesmo em outro lugar aqui por perto, quando alguém nos convida, mas não deixamos de jogar, não." (Entrevistado 2)". Outro associado citou o mesmo caso: "Sempre jogamos. Se não der no Clube, jogamos em outros lugares" (Entrevistado 5).

Também é importante salientar que esta prática esportiva é oferecida no Clube durante a semana e aos finais de semana, diferentemente das outras, como a musculação e a ginástica, em que em alguns dias as salas ficam fechadas e não há aulas, nem possibilidade de utilização desses espaços pelos associados. Isto também acontece com o futebol oferecido às crianças: há aulas e eventos durante a semana e aos finais de semana, inclusive.

Todo domingo, logo a partir das nove horas, há um grupo de associados do Clube que recebe visitantes para jogar futebol. É um evento que inclui a presença de árbitros e, ainda, de outros associados que torcem e vibram pelo Clube. Nas observações, foi possível notar a presença dos associados, homens e mulheres, de diversas faixas etárias assistindo aos jogos e torcendo pelo time do Clube.

Após o término do jogo, percebo que o time do Clube da Rhodia ganha. Os jogadores se reúnem no centro do campo, conversam sobre o jogo e, depois, observo um interessante ritual, eles rezam abraçados, em círculo, agradecendo a vitória. Após a oração, dirigem-se ao vestiário (DIÁRIO DE CAMPO, 07/03/2010). 
Embora não praticassem o futebol, era possível identificar mulheres (adultas e adolescentes) moradoras da Vila Holândia que assistiam aos jogos e torciam pelo Clube. Conseguimos entrevistar uma delas. Ela era praticante de ginástica no Clube, mas afirmou que também frequentava o Clube como espectadora e torcedora do futebol.

O futebol também estimula outros contatos sociais entre os usuários do Clube. É comum eles promoverem churrascos e "cervejadas" após os jogos dos finais de semana (e, às vezes, durante a semana). Por meio das observações também foi possível identificar alguns moradores da Vila Holândia presentes em todos os eventos.

\begin{abstract}
Minutos após o jogo, vou para a cantina e reconheço lá alguns participantes e também alguns moradores da Vila Holândia que jogaram. À medida que vão chegando, combinam como será a "cervejada" - termo utilizado por um deles - quem pagará e como. Comentam que há um grupo também fazendo churrasco no quiosque. O dono da cantina comenta que isto é comum, tanto o tomar cerveja, quanto os churrascos após os jogos. Vou até próximo do quiosque e reconheço outros jogadores, preparando o churrasco (DIÁRIO DE CAMPO, 20/03/2010).
\end{abstract}

Podemos afirmar, assim, que, tomando por base Simmel (1983, apud GONZALEZ, 2007), o envolvimento nas práticas corporais de lazer neste espaço, particularmente o futebol, proporciona, ainda, outra forma de interação, já que a tal "cervejada" sempre acompanha a prática do futebol.

As entrevistas e as observações nos mostraram que o futebol proporciona uma forma particular de interação, de sociabilidade, segundo Simmel. Nele, os participantes não buscam nenhuma finalidade a não ser a vivência lúdica desta prática corporal. Embora a maioria dos associados participantes desta prática seja de funcionários da empresa Rhodia, não é o trabalho que promove esta interação e, sim, a prática do futebol, que é estendida a outros locais fora do Clube. A partir das observações, também é possível destacar que os moradores da Vila Holândia - aqueles que praticam o futebol - se apropriam do Clube da Rhodia como um espaço significativo de lazer, imprimindo suas marcas. A ausência em um jogo, por exemplo, ou mesmo a algum evento do futebol (jogos aos domingos), é cobrada pelos parceiros.

O jogo ainda não começou, os praticantes estão se aquecendo e alguns participantes chegam aos poucos. Identifico um morador da Vila Holândia chegando atrasado. Um dos colegas pergunta o motivo de sua falta no treino ante- 
rior e no jogo de domingo. O morador justifica uma gripe forte e afirma estar sentindo já a falta da "bola". Ouço esta cobrança também feita a outros praticantes não moradores da vila Holândia. (DIÁRIO DE CAMPO, $14 / 10 / 2010)$.

Apropriação, aqui, é entendida como um processo de interação do sujeito, de uma vivência interiorizada com o seu meio externo (POL, 1996). Smolka (2000) considera a apropriação como "modos de tornar próprio, de tornar seu; adequado, pertinente aos valores e normas socialmente estabelecidos" (p. 28). É um processo de identificação no espaço e no tempo com uma influência mútua entre espaço e sujeito. Ao mesmo tempo em que há essa identificação, os sujeitos também transformam os espaços, imprimindo neles suas marcas.

Para Pol (1996), apropriar-se de um lugar não é somente fazer dele uma utilização reconhecida, mas também estabelecer uma relação, integrálo em suas próprias vivências e ser ator de sua transformação, ou seja, transformá-lo em algo significativo para os sujeitos. Embora a Vila Holândia seja muito próxima do Clube, é a empresa Rhodia que promove o pertencimento a este espaço de lazer.

Após as entrevistas com os moradores que frequentam e se apropriam do Clube da Rhodia, procuramos por aqueles que haviam citado, em pesquisa anterior (AMARAL et al., 2009), ter frequentado o Clube em épocas passadas e não o frequentam mais. Encontramos oito moradores nesse contexto. Realizamos entrevistas com eles com o objetivo de levantar quais os motivos os levaram a não frequentarem mais o Clube. Esses moradores citaram as seguintes justificativas: a falta de tempo, o fato de serem idosos e não se sentirem à vontade para frequentar o Clube, o pertencimento a uma religião que não permite que se frequente alguns lugares. Um dos moradores ainda comentou que, por não trabalhar na Rhodia, não pode ser associado e não frequenta mais. Afirmou ter frequentado somente quando foi apresentado por um amigo que trabalhou na Rhodia no passado, mas este se mudou da Vila. Esse morador afirmou que, se pudesse, gostaria de continuar como associado, pois o Clube possibilita a ele a vivência de muitas atividades de lazer. "Naquela época, o Clube era mais perto daqui e animado. Hoje, ele fica mais longe, eu trabalho e não tenho tempo" (Entrevistada 11).

Assim, esses moradores não se apropriam do clube, ao contrário dos outros entrevistados citados anteriormente. 


\title{
Considerações Finais
}

As observações e entrevistas nos apontaram elementos significantes para compreender a relação do Clube com os moradores da Vila Holândia e dos mesmos com o Clube, em relação às práticas corporais oferecidas.

Podemos afirmar que o futebol é a prática mais vivenciada pelos associados do sexo masculino, tanto no Clube quanto fora dele, na comunidade e em outros espaços da cidade, mas não podemos afirmar que o Clube é um espaço por excelência de formação para o lazer fora dele e nem viceversa. Mas podemos destacar que a sociabilidade acontece nele, e outras interações também são vivenciadas a partir desse esporte.

Porém, não podemos estender esta análise da sociabilidade e outras associações nas outras práticas corporais vivenciadas no Clube pelos moradores da Vila Holândia, como a ginástica e a musculação. Mesmo assim, podemos afirmar que os moradores que frequentam o Clube se apropriam dele e o reconhecem como um espaço significativo de lazer.

Acreditamos que os gestores deveriam repensar sua política de associação, uma vez que eles têm permitido a pessoas de bairros próximos (Cidade Universitária, por exemplo), de alto poder aquisitivo, moradores de condomínios se associarem ao Clube e impedido a maioria dos moradores da Vila Holândia. A nosso ver são estes moradores do entorno do Clube da Rhodia os que mais necessitam de espaços e oportunidades de lazer.

\section{THE RHODIA CLUB AND THE RESIDENTS OF THE VILLAGE HOLAN- DIA - CAMPINAS / SP}

\begin{abstract}
This work is part of a broader research titled Uses of leisure time in Vila Holândia in which we investigate which practices, spaces and places of reference are used to enjoy leisure time. The Rhodia Club was one of the spaces for free time and enjoyment of leisure mentioned as important by the residents of this Vila, located in the Barão Geraldo district, in Campinas, state of São Paulo. Thus, the objective of the study was to understand the relationship between the Club and the residents of Vila Holândia, and of the latter with the Club, in what is called leisure time and in bodily practices promoted by the Institution. The purpose was to diagnose which bodily practices experienced at the Rhodia Club are relevant to the residents of Vila Holândia, and also to identify the relationship/impact that they produce in leisure time outside the Club. A search of the literature was performed, as well as observations and semi-structured interviews. The analyses showed that gymnastics, bodybuilding and soccer are the most significant bodily practices for the residents. Soc-
\end{abstract}

Pensar a Prática, Goiânia, v. 17, n. 3, p. 651-666, jul./set. 2014 
cer is the bodily practice that is most experienced by the men, both at the Club and in the community and other spaces in town. It provides other types of interactions besides sociability itself.

Keywords: Rhodia Club. Free Time. Leisure. Bodily Practice. Sociability.

\section{EL CLUB RHODIA Y LOS RESIDENTES DE LA ALDEA HOLANDIA - CAMPINAS / SP}

\section{Resumen}

Este trabajo hace parte de una investigación más amplia, denominada Usos del tiempo libre en Villa Holândia en la cual investigamos cuales son las prácticas, los espacios y los lugares de referencia para el disfrute del tiempo libre. El Club de la Rhodia fue uno de los espacios para el tiempo libre y disfrute del ocio apuntado por los habitantes de esta Villa, situada en el distrito de Barão Geraldo, Campinas, São Paulo como importante. Así, el objetivo del estudio fue comprender la relación del Club con los habitantes de Villa Holândia y de estos con el Club, en el tiempo denominado libre y en las prácticas corporales promovidas por la Institución. Tuvo como propósito diagnosticar cuales prácticas corporales vividas en el Club de la Rhodia son relevantes para los habitantes de Villa Holândia, así como identificar la relación/impacto que estas producen en el tiempo libre fuera del Club. Fueron realizadas investigación bibliográfica, observación y entrevistas semiestructuradas. Los análisis mostraron que la gimnasia, la musculación y el futbol son las prácticas corporales más significativas para los habitantes. El futbol es la práctica corporal más ejercida por los hombres, tanto en el Club como en la comunidad y en otros espacios de la ciudad. Este proporciona otros tipos de interacción de sociabilidad en sí.

Palabras-claves: Club de la Rhodia. Tiempo Libre. Ocio. Prácticas Corporales. Sociabilidad.

\section{Referências}

AMARAL, Sílvia Cristina Franco; NAKAMOTO, Henrique Okajima; PEREIRA, Ana Paula Cunha. Usos do tempo livre na Vila Holândia - Campinas - SP. In: XVI Congresso Brasileiro de Ciências do Esporte / III Congresso Internacional de Ciências do Esporte, 2009, Salvador-BA. Anais... Salvador-BA: UFBA, v. 1, p. 1-9, 2009.

ESTATUTO ASSOCIAÇÃO DESPORTISTA CLASSISTA RHODIA PAULÍNIA (ADCRP), Campinas, março 2009. 
BURKE, Peter. A história social dos clubes. São Paulo: Folha de São Paulo, Caderno Mais, 23 fev. 2002.

CALDEYRO, Verônica Sabatino. As Cidades que desenham Barão Geraldo. 2005. 131 f. Dissertação (Mestrado em Engenharia Civil) - Faculdade de Engenharia, Arquitetura e Urbanismo. Universidade Estadual de Campinas, Campinas, 2005.

CAMARGO, Luiz Octávio de Lima. Educação para o lazer. São Paulo: Moderna, 1998.

CONJUNTO PAULÍNIA 50 ANOS. Campinas, Rhodia, 1992.

GONZALEZ, Fernando Jaime. Sociabilidades e práticas corporais: leitura de uma relação. In: STIGGER, Marco Paulo et all. (Orgs) O Esporte na cidade: estudos etnográficos sobre sociabilidades esportivas em espaços urbanos. Porto Alegre, 2 ed., Editora da UFRGS, 2007.

POL, Enric. La apropriacion del Espacio. In: POL, Enric.; INIGUEZ, L. Cognicion, representation y apropriacion del espacio. Publicaciones de $\mathrm{La}$ Universitat de Barcelona. Barcelona, 1996.

RIBEIRO, Olívia Cristina Ferreira. Atividades recreativas em clubes. In: SCHWARTZ, Gisele (Org). Atividades Recreativas. Rio de Janeiro: Guanabara Koogan, 2004.

SMOLKA, Ana Luiza Bustamante. O (im)próprio e o (im)pertinente na apropriação das práticas sociais. Cadernos Cedes, Campinas, ano XX, n. 50 , abril/2000.

Recebido em: 22/08/2013

Revisado em: 08/09/2013

Aprovado em: 02/10/2013

Endereço para correspondência:

oliribeiro@uol.com.br

Olívia Cristina Ferreira Ribeiro

Universidade Estadual de Campinas - UNICAMP

Pensar a Prática, Goiânia, v. 17, n. 3, p. 651-666, jul./set. 2014 
Faculdade de Educação Física - FEF

Avenida Érico Veríssimo, 701, Cidade Universitária Zeferino Vaz, Barão Geraldo CEP 13.083-851, Campinas, SP, Brasil 